\title{
Mudanças de paradigmas para uma Gestão Educacional Inovadora
}

\author{
Isadora Siqueira Mafra ${ }^{2}$ \\ Universidade do Vale do Itajaí \\ Itajaí, Santa Catarina, Brasil \\ isa@univali.br
}

\author{
Naiara Gracia Tibola ${ }^{1}$ \\ Universidade do Vale do Itajaí \\ Itajaí, Santa Catarina, Brasil \\ tibola@univali.br
}

\section{RESUMO}

Este estudo tem como problemática os paradigmas que rondam a temática de inovação na gestão escolar. Conceitua escola como a principal instituição para socialização de conhecimento e o gestor escolar como peça chave na condução das atividades. Nesse sentido, aponta-se estudos anteriores que expressam a diferença entre administrador e gestor, a partir de um paradigma fabril como dominante. Ressalta-se a importância da transição para um pensamento mais aberto, inovador, coletivo e criativo, a fim de mobilizar a comunidade escolar para que se estabeleça um ambiente favorável para uma instituição inovadora, eficaz e de qualidade. $\mathrm{O}$ objetivo é compreender quais as principais mudanças de paradigmas relacionadas à gestão escolar são necessárias para a estruturação de um ambiente inovador e, ainda, descrever as mudanças de paradigmas da gestão escolar e apontar e enunciar práticas inovadoras para a gestão escolar. É uma pesquisa de abordagem qualitativa, classificada como exploratória e bibliográfica, pois foi realizada a partir de registros disponíveis advindos de pesquisas anteriores, como livros e artigos. As práticas de inovação na gestão escolar trazidas no artigo exemplificam ótimas gestões democráticas que conseguiram engajar a comunidade escolar, gerando comprometimento, pertencimento e colaboração de todos os atores envolvidos e mostram que não é preciso de muito para poder inovar e mudar o paradigma que envolve a temática.

\section{PALAVRAS-CHAVE}

Paradigma; Gestão Escolar; Educação; Inovação.

\section{Introdução}

O mundo se transforma em alta velocidade. Produtos se renovam semana após semana, as tecnologias avançam além do que podemos ver, muitas facilidades vêm sendo criadas, produtos e processos integrados, novas formas de viver e se relacionar estão sendo incutidas na nossa realidade para atender à novas demandas.

A nova configuração social demanda um novo olhar sobre

\footnotetext{
${ }^{1}$ Professora da Universidade do Vale do Itajaí - UNIVALI. Mestre em Educação (FURB). Doutoranda em Educação (UNIVALI).

${ }^{2}$ Pós-graduada em Gestão Universitária - UNIVALI e Inovação na Educação UNIVALI
}

a gestão da escola e, nesse aspecto, parece que as mudanças são menos evidentes ainda. A ideia de uma gestão escolar com base no paradigma fabril, que deixa de lado processos inovadores, ainda é dominante ${ }^{[1]} \mathrm{e}$, assim, apesar de as escolas estarem se modernizando com novos equipamentos e tecnologias, a gestão escolar não acompanha as mudanças requeridas para a construção do contexto de uma educação inovadora, que pouco tem a ver com tecnologia.

Bezerra $^{[2]}$ infere que de nada adianta ter equipamentos de ponta sem trabalhar o indivíduo. Antes de criar a inovação, que tem sido considerada a principal habilidade de gerenciamento do século XXI, é necessário criar o inovador.

O mundo evolui, os conceitos se alteram e as mudanças de paradigma são inerentes a todo esse movimento, inclusive no meio educacional. É necessário dar novo significado à visão e à prática dos gestores educacionais, que muitas vezes ainda trabalham como administradores escolares, introduzindo novas formas de pensar e agir na Gestão Escolar.

Mesmo que vagarosamente, as modificações tecnológicas e de inovação estão acontecendo nos espaços escolares e vêm ganhando espaço. $\mathrm{O}$ ano de 2020 trouxe mudanças de uma forma atípica, por conta da pandemia do COVID-19, de forma que as pessoas estão se adaptando a um "novo normal", os processos sofreram mudanças bruscas e repentinas e todos foram obrigados a se adaptar. Possivelmente esta mudança será permanente e aqui temos um ponto de partida para repensar e ressignificar os paradigmas que desvirtuam a construção de uma gestão escolar inovadora, aprendente e adequada aos novos tempos.

Para a estruturação deste trabalho autores como Amorim ${ }^{[1,}$ ${ }^{3]}$, Ogawa e Filipak ${ }^{[4]}$, Coelho e Unglaub ${ }^{[5]}$, Vasconcellos ${ }^{[6]}$ e Martins $^{[7]}$ contribuíram para a escrita e para atingir aos objetivos aqui propostos. A busca da temática partiu das angústias de uma pós-graduanda em Inovação na Educação que, durante todo o curso e leituras realizadas, teve a impressão de que as "supostas" inovações sugeridas pelos diversos autores lidos já estavam mais do que claras e que, por muitas vezes, já eram até antigas, porém nunca foram postas em prática ou, se foram, foram por muitos poucos agentes, que, num percentual, não se tornam relevantes o suficiente para podermos constatar que houve de fato uma melhoria nos processos de inovação em gestão e em educação em um contexto geral.

A partir da revisão de documentos previamente selecionados, o presente artigo busca descrever quais os paradigmas que rondam a temática da gestão escolar inovadora e compreender quais as principais mudanças são 
necessárias para a estruturação de um ambiente inovador. Serão apontadas e enunciadas novas práticas inovadoras na gestão escolar, a fim de evidenciar a importância de mudar o pensamento e efetivar o aprendido para obter sucesso na prática da gestão escolar inovadora.

\section{Revisão da Literatura}

A instituição escola é o centro dos sistemas educacionais, onde é realizado o processo de conhecimento e de socialização de informações. É o núcleo gerador de conhecimento e da sua ampliação ${ }^{[6]}$. Amorim [2017, p. 75] corrobora, quando diz que:

As escolas têm uma função secular de transmissoras dos saberes produzidos socialmente pelas comunidades onde elas atuam. Isto ocorre de geração para geração, em cada etapa histórica, colocando as instituições de ensino como sendo uma organização marcante na vida das pessoas. Essas instituições procuram mudar em seu ambiente pedagógico e institucional para criar uma nova cultura que seja individual e coletivamente referenciada, com práticas individuais e sociais que se aproximam e se contradizem ao mesmo tempo, servindo de espaço inovador. É um movimento dialético que a sociedade realiza através das instituições de ensino para aproximar o passado ao presente e o presente abre espaços dinâmicos para aproximar o futuro, antecipando e revelando experiências e saberes socioeducacionais, socioemocionais e sociopessoais que aprofundam e engrandecem a perspectiva histórica da educação e da escola, o dever ser da educação.

A necessidade legal de um diretor escolar surge, segundo Antunes $^{[8]}$, somente a partir de 1847 , porém a discussão sobre seu papel só vem à tona em 1890, após a proclamação da República no Brasil. Na década de 1930, no início do período industrial, começa-se a falar em um administrador escolar, mas o cargo ainda está muito vinculado a questões administrativas em detrimento das pedagógicas, tomando como modelo as concepções de Taylor, Fayol e Weber ${ }^{[9]}$.

Nos anos de 1931-1935, são noticiados os primeiros movimentos de participação na gestão da escola pública [BASTOS, 2002, apud OGAWA; FILIPAK, 2013, p. 97], porém a gestão democrática só passa a ter força de lei a partir da Constituição Federal de 88. Nesse contexto, surge uma figura que demanda relações com a comunidade escolar, por meio de decisões e ações partilhadas. A função do gestor tem no diálogo um importante instrumento na execução da gestão escolar, mas ainda com viés político [OGAWA; FILIPAK, 2013, p.97].

O gestor escolar, antes denominado administrador escolar, é a figura principal no exercício da administração - não mais política, mas de uma forma que construa e consolide um projeto dinâmico para as escolas e que garanta a qualidade e o sucesso educacional de sua instituição. Ao conduzir as atividades de forma coletiva, participativa e criativa, o gestor está no caminho de uma gestão escolar inovadora.

Amorim $^{[3]}$, baseado em estudos de Martins [1999], entende por administrador escolar aquele que dirige utilizando-se de burocracias, hierarquia e de participação individual como chave do processo. Já o gestor escolar, tem a visão da escola como um todo, onde todos fazem parte do mesmo processo, com responsabilidades específicas, ações planejadas e resolução de problemas de forma coletiva.

Antunes ${ }^{[8]}$ diz que a troca do termo administração por gestão, não significa apenas uma mudança terminológica, mas sim conceitual e paradigmática e que pode ter diferentes significados. A autora traz que alguns entendem apenas como a transição do campo do conceito, que passa de empresarial para educacional. Outros, que o conceito de gestão ultrapassa o de administração, já que envolve a participação ativa da comunidade nas decisões internas [LUCK, 2000 apud ANTUNES, 2008, p.9]. E outros, ainda, entendem administração por um conceito mais amplo, já que é utilizado para abranger a política educativa, e gestão como a função executiva destinada a pôr em execução políticas previamente definidas [BARROSO, 2001 apud ANTUNES, 2008, p.9].

Apesar dos diferentes entendimentos sobre as mudanças terminológicas, a gestão administrativa inovadora, parte do paradigma na qual todos participam do processo e contribuem para a consolidação de melhorias positivas e significativas no ambiente escolar e também no sistema de ensino, no qual gestores, professores, alunos e pessoal técnico e administrativo, juntos, constroem uma cultura escolar que contribui para o desenvolvimento de competências e habilidades inovadoras, assim fortalecendo o trabalho do gestor ${ }^{[3]}$.

O espaço em que ocorre a gestão precisa ser, conforme Antunes [2008, p. 09], “[...] sinônimo de ambiente autônomo e participativo, o que implica trabalho coletivo e compartilhado por várias pessoas para atingir objetivos comuns". A autora Luck [2000 apud ANTUNES, 2008, p.9] corrobora ainda que o diretor passa de um fiscalizador, controlador e que centraliza em si as decisões, para um gestor mobilizador, orquestrador de atores, articulador da diversidade que constrói um ambiente educacional e que promove a formação de seus alunos de forma segura.

Para atingir os objetivos do cargo, é importante que a pessoa que estiver nesta função, além de ter o pensamento aberto à inovação dos processos e voltada à coletividade, seja qualificada e busque sempre estar atualizada em relação às práticas de gestão. Um estudo de Amorim [2017, p. 72], baseado no Censo Escolar de 2013, divulgado pelo INEP, que definiu o perfil do atual gestor educacional concluiu que:

$22 \%$ dos dirigentes ainda são escolhidos pelo processo de indicação política; considerando-se o total de 54 mil dirigentes entrevistados, $22 \%$ correspondem a 11.880 dirigentes que ainda são agraciados politicamente para exercer uma função que, muitas vezes, eles não têm o menor preparo institucional, numa clara demonstração da falta de critérios de qualidade na escolha desses dirigentes.

Ainda vemos, portanto, alguma desqualificação decorrente da influência política na contratação das peças chave para a construção da escola inovadora que tanto queremos. Os processos escolares precisam ser eficazes e de qualidade, tendo como alguns indicadores: formação; qualificação; desempenho; níveis de satisfação e colaboração do pessoal; liderança e tomada de decisão da direção; articulação do currículo; envolvimento da comunidade externa, principalmente alunos, pais e parcerias $^{[7]}$; que só poderão 
ser alcançados se geridos com excelência por pessoas, prioritariamente, qualificadas.

Com o novo entendimento sobre as atribuições do gestor, aumentaram os debates acerca da necessidade de profissionalização destes profissionais como condição para a melhoria da qualidade da educação básica. Como resultado dos debates, surgiram as capacitações de dirigentes, pautadas nas competências gerenciais ${ }^{[8]}$.

Coelho e Unglaub ${ }^{[5]}$ apontam para a necessidade de um novo perfil de gestor para acompanhar esse novo tempo. Veem, ainda, a necessidade da profissionalização da gestão de ensino e de pautar ações educacionais para atender um novo patamar de concorrência e competitividade. Uma nova gestão, com visão aberta a mudanças, provocadora de transformações e que colabore com melhorias significativas na organização educacional.

Ogawa e Filipak [2013, p. 99] reforçam que é emergente a necessidade de profissionalização do gestor, concedendo maior preparo para que a gestão da escola seja verdadeiramente democrática e com foco na qualidade de ensino. Qualificar o gestor escolar significa instrumentalizá-lo quanto aos aspectos técnicos e pedagógicos da gestão escolar e, principalmente, fomentar a ampliação do entendimento escolar no Brasil, que implica em transformar todos os processos que objetivam a qualidade de ensino na escola pública brasileira.

Além da profissionalização, é clara a necessidade de que os gestores sejam pessoas abertas a mudanças, pois, para Coelho e Unglaub $^{[5]}$, a educação precisa estar à frente das mudanças e inovações. Ao contrário, ainda percebemos grande resistência dos educadores e gestores em relação aos processos condutores. Os autores inferem que:

Se uma instituição educacional pretende passar por um processo de inovação, ela deverá se preocupar em formar/capacitar todo o corpo docente, administrativo e operacional para que os processos de inovação sejam desenvolvidos em unidade e coerência. [COELHO; UNGLAUB, 2012, p. 4].

Em definitivo, a diversidade e complexidade das tarefas e competências necessárias para uma liderança qualificada requer uma aproximação dos gestores com o tema, para que a mudança de paradigma ocorra e consiga mobilizar a comunidade escolar no sentido de criar clima e cultura favoráveis para uma instituição, de fato, inovadora, eficaz e de qualidade.

Apesar de o gestor ter um papel fundamental na democratização da escola, Antunes ${ }^{[8]}$ afirma que o processo não é uma via de mão única, mas sim uma construção coletiva entre os diferentes atores em cada unidade escolar. "A participação não depende de alguém que "dá" abertura ou "permite" sua manifestação. Democracia não se concede, conquista-se, realizase" [HORA, 1994, p. 133] ${ }^{[10]}$.

Antunes $^{[8]}$ infere, ainda, que a democratização da gestão educacional compreende a cultura escolar, seus processos e a articulação entre os aspectos e mudanças históricas, políticas e sociais que envolvem a escola e os atores. É romper com o modelo autoritário, burocratizado e centralizador e dar vez aos interesses coletivos, favorecendo a compreensão do mundo, de si mesmo, dos outros e das relações sociais essenciais para a construção de um trabalho coletivo.
O processo é lento, pois depende do entendimento de cada ator referente ao assunto e ao seu papel por trás do cargo que exerce. Há que existir o engajamento pessoal na busca do bem coletivo e da comunidade em que as escolas estão envolvidas. Um gestor que seja propagador de todas as boas práticas, que consiga com que os trabalhos sejam cada vez mais inspiradores e inovadores a ponto de contagiar a todos da rede, que não desanime frente aos obstáculos e à baixa adesão e que fortaleça o sentido do seu cargo, para que todo uma estrutura mude para melhor.

\section{Procedimentos Metodológicos}

Trata-se de uma pesquisa de abordagem qualitativa, que busca compreender um fenômeno em seu ambiente natural, onde este ocorre e do qual faz parte [BOGDAN; BIKLEN apud KRIPKA; SCHELLER; BONOTTO, 2015]. Apoia-se nas interações entre os sujeitos sociais, que produzem material passível de interpretação e análise e que pode ser utilizado para fundamentar a construção de conhecimento relacionado a determinado fenômeno ${ }^{[12]}$.

Com referência à natureza das fontes utilizadas para abordagem, a pesquisa é classificada como bibliográfica, pois foi realizada a partir de registros disponíveis advindos de pesquisas anteriores, como livros e artigos. Utiliza-se dados já trabalhados e registrados por outros pesquisadores, de forma que os textos se tornam fontes do tema pesquisado e a pesquisa é trabalhada a partir das contribuições dos autores estudados ${ }^{[13]}$, propiciando o exame do tema sob novo enfoque e chegando a conclusões inovadoras ${ }^{[14]}$.

É uma pesquisa exploratória, que busca levantar informações sobre determinada temática, delimitando o campo de trabalho ${ }^{[13]}$, sendo que a coleta de dados se deu por meio de análise documental, a partir da "identificação, levantamento, exploração de documentos fontes do objeto pesquisado e registro das informações retiradas nessas fontes e que serão utilizadas no desenvolvimento do trabalho" [SEVERINO, 2007, p.124]. O objetivo é investigar os documentos a fim de descrever e comparar as tendências, diferenças e outras características ${ }^{[15]} \mathrm{e}$ gerar novos conhecimentos e novas formas de compreender os fenômenos ${ }^{[11]}$.

Para o levantamento documental foram feitas buscas por documentos integralmente disponíveis em formato eletrônico e gratuito nos bancos de dados da Scielo Brasil, Google Acadêmico e também em sites de eventos da área Educacional com as palavras-chaves: gestão escolar, inovação, paradigma e gestor escolar e também feitas buscas em bibliotecas digitais e físicas por títulos que contivessem as temáticas: administração escolar, gestão escolar, gestão inovadora e gestão participativa.

A busca contemplou trabalhos publicados nos últimos 15 anos: de 2006 a 2020, além de complementos clássicos de datas anteriores. Foram consultados 21 artigos e 12 livros relacionados à temática, sendo escolhidos, entre estes, 9 artigos e 7 livros para compor o presente trabalho, divididos nas categorias Gestão Democrática e Inovação na Gestão Escolar. Por tratar-se de pesquisa documental, o trabalho não foi submetido ao Comitê de Ética em Pesquisas. 


\section{Inovação na Educação - Práticas Exitosas}

De forma sucinta, se faz perceptível o avanço na forma de condução das escolas por parte de gestores que buscam inovar em seus espaços educativos. Uma gestão inovadora, participativa e digna de ser exemplo e inspiração para outros gestores.

Dispomos no Brasil de alguns concursos, premiações, relatos de casos e grupos de estudos que exemplificam boas práticas na gestão escolar, valorizando e colocando as ações destes "anônimos" em voga para que inspirem a todos educadores. O presente trabalho buscou dois casos para exemplificar e inspirar estas ações que, há muitos anos já vêm sido faladas, mas que muito pouco foram postas em prática, seja por falta de qualificação, de vontade ou de impedimentos burocráticos.

Com estes exemplos pudemos perceber que não é preciso muito para fazer acontecer, inovar e servir de exemplo. Não é preciso de muito dinheiro, tecnologias, supercomputadores, mas sim de gestores que executem ações que estejam pautadas na empatia, em pensar em como poder ajudar de forma mais eficaz, de forma que supra as necessidades de todos e que, justamente por isso, todos possam ter voz e participar ativamente.

\subsection{Projeto Acolher para todos envolver e aprender - Prêmio Educador Nota Dez 2020.}

Desenvolvido na Escola Municipal Professor Waldir Garcia, no Bairro São Geraldo, município de Manaus/AM, em 2019, o Projeto Acolher para todos envolver e aprender, de autoria da professora Lúcia Cristina Cortez de Barros Santos, uma das dez vencedoras do Prêmio Educador Nota Dez 2020, promove a inclusão e dá espaço ao diálogo na escola.

$\mathrm{Na}$ prática, a comunidade que já era considerada de alta vulnerabilidade social passou a receber um número muito grande de imigrantes haitianos e venezuelanos. Reconhecendo que estes eram geralmente excluídos das outras escolas, a escola fez da inclusão o princípio norteador de todo o projeto. Além da comunidade imigrante, a escola recebe também deficientes, alunos com distorção de idade e série e em situação de risco, todos excluídos do processo escolar.

$\mathrm{Na}$ escola, os alunos encontram acolhida e respeito, rompendo o discurso da impossibilidade e dando visibilidade ao invisível. Além disso, a diretora conseguiu implementar uma gestão democrática, desburocratizando relações, estabelecendo vínculos, engajando e dialogando com todos os atores da comunidade escolar.

As inovações principais foram a troca das carteiras individuais por mesas redondas; não há filas ou reprovação; são feitas avaliações internas e externas que permitem revisar o processo de ensino, pois o foco central é a aprendizagem; as decisões são feitas em assembleias, onde os alunos atuam como protagonistas; cada uma das 223 crianças escolhe um tutor, que a acompanha até o final do $5^{\circ}$ ano; o envolvimento das famílias; a troca de experiências e valorização das diferentes culturas existentes na escola.

A escola Waldir Garcia optou também pelas metodologias ativas que não ensinam somente o conteúdo, mas desenvolvem competências essenciais para realizações na vida pessoal, onde o estudante é o protagonista da sua aprendizagem.

Destaca-se, ainda, a articulação do projeto com outros entes da sociedade, como a Unidade Básica de Saúde (UBS) da área, que disponibiliza equipe para acompanhar a saúde das crianças; o Coletivo Escola Família do Amazonas, organização da sociedade civil que apoia as tutorias; e as universidades Estadual e Federal do Amazonas, que oferecem oficinas, palestras e estagiários para auxiliar nas demandas da comunidade escolar.

Para contornar a questão do idioma, foram feitas parcerias com a Secretaria Municipal de Educação e com o Consulado da Colômbia para um curso-piloto de espanhol para os estudantes não falantes da língua. Além disso, a escola atua com a Igreja São Geraldo, que fica perto da escola e é local de apoio aos imigrantes, onde é ministrado um curso de português às famílias estrangeiras. Em parceria com a paróquia, um professor haitiano voluntário ensina crioulo aos funcionários da escola. Atitudes simples, mas empáticas e respeitosas que fizeram a diretora se destacar e ser exemplo nacional de boas práticas em gestão educacional.

O projeto, que surgiu justamente das dificuldades educacionais encontradas, tem como a inclusão uma das principais premissas. A troca de experiências, a valorização das diferentes culturas, a aprendizagem aplicada a solucionar os desafios da vida e a transformação da comunidade escolar em agentes de transformação, deram ao projeto o Prêmio Educador Nota Dez no ano de 2020.

Mesmo na pandemia do COVID-19, onde as atividades presenciais nas escolas do Brasil e do Mundo foram suspensas ou migradas para o virtual, a escola fez campanha para arrecadação de televisões, celulares e dinheiro, que foi usado para a compra de equipamentos doados às famílias que ficaram sem acesso às aulas virtuais, para que os trabalhos não parassem e que a comunicação e o vínculo afetivo entre escola e comunidade se mantivessem, apesar da distância.

A campanha foi além dos aspectos educacionais e a rede colaborativa criada pela escola organizou-se no sentido de fornecer ajuda, inclusive com doação de alimentos, aos que mais necessitam. Outro aspecto positivo foi o fato de a escola já trabalhar com um modelo que estimula a autonomia dos alunos, que foi fundamental para a adaptação destes ao ensino remoto.

\subsection{Prática de aprendizagem colaborativa com a utilização de diferentes instrumentos tecnológicos no ambiente escolar}

Desenvolvido na gestão coletiva do Professor Paulo Sérgio Cabral, na Escola Básica Prof. ${ }^{a}$ Maria Dutra Gomes, localizada no bairro Dom Bosco, cidade de Itajaí/SC, a prática teve início no ano de 2018, quando da implantação da Base Nacional Comum Curricular - BNCC, baseada na Cultura Digital, uma das dez Competências Gerais a ser desenvolvida na Educação Básica.

Com a prática, a gestão buscou implementar soluções inovadoras que otimizem os processos de ensino-aprendizagem, estimular a criatividade e autonomia dos alunos, melhorar a 
qualidade do tempo destinado à aprendizagem em sala de aula e formar professores inovadores capazes de motivar os alunos no processo de aprendizagem com o uso da tecnologia.

A prática visou transformar a escola em um ambiente inovador, utilizando-se das tecnologias em seu favor no intuito de tornar as aulas e práticas mais atrativas aos alunos, explorar novas ideias, ampliar conceitos, criar estratégias inteligentes para a otimização dos processos educacionais e desenvolver competências básicas em cultura digital nos alunos, para que eles próprios consigam otimizar o uso das ferramentas tecnológicas que estão ao seu alcance.

Há, atualmente, uma infinidade de aplicativos e páginas online que podem auxiliar os professores em sala de aula no desenvolvimento de suas atividades. Grande parte gratuitas ou financeiramente acessíveis e que podem ser acessadas individualmente, pelo equipamento pessoal de cada aluno, bastando ter conexão à internet disponibilizada pelas escolas para que as aulas sejam mais atrativas, significativas e proveitosas para os alunos.

Partindo deste fato, e ao contrário da maioria das escolas que proíbem o uso do celular em sala de aula, uma das principais mudanças na Escola Básica Prof. ${ }^{\text {a }}$ Maria Dutra Gomes foi a permissão para o uso consciente e inteligente do celular em sala de aula, assim contornando os transtornos que a proibição do uso causa para os professores, que têm que ficar fiscalizando, e também para propiciar uma melhora na aprendizagem e engajamento dos alunos.

Inicialmente o uso foi permitido no horário do recreio, com a indicação de alguns aplicativos, aproximando de forma cooperativa os jovens e a equipe gestora, fazendo-os entender a forma de trabalhar da escola. Com ações bem planejadas, o uso do celular passou a ser permitido como complemento às atividades de sala. A organização escolar passou - e deve - ser vista como cultura e ser disseminada pelos atores, além da necessidade do planejamento e organização da instituição e das atividades.

Concomitantemente, e ao longo dos meses seguintes, foram feitas formações com os docentes, discentes e equipe de colaboradores em serviço e nas paradas pedagógicas, em parceria com o instrutor de informática e professores da própria escola que já tinham mais experiência com ferramentas como o Google Forms e Google Classroom, com as metodologias ativas, sala de aula invertida, gamificação e ensino híbrido, no intuito de qualificá-los para o uso das ferramentas e aplicabilidade do celular nas atividades.

Houve também, em parceria com a Diretoria de Tecnologias Educacionais da Secretaria Municipal de Educação, a ampliação da rede wi-fi em $100 \%$ dos ambientes da escola, proporcionando internet de qualidade e velocidade à comunidade escolar. Desta parceria também foi conseguido 7 tablets para uso de aproximadamente 30 alunos com deficiências intelectuais, motoras e físicas. Os equipamentos são usados em aulas previamente planejadas pelo professor e com aplicativos também previamente selecionados, não como forma de ocupar os alunos, mas sim como forma de estabelecer atividades diferenciadas a eles e condizentes à sua condição. Para otimização das atividades, foram feitas também formações com as agentes de apoio em educação especial, juntamente com os professores regentes.

O uso tecnológico dos celulares no processo avaliativo foi outra ação que acabou reduzindo significativamente a utilização de papel, principalmente nos anos finais, reforçando ainda questões de sustentabilidade entre os alunos. A prática resultou em menor utilização do Laboratório de Informática, que muitas vezes conta com computadores sucateados, lentos, e em quantidade insuficiente, por vezes forçando os alunos a dividirem computadores. Com a permissão do uso do celular, em vez do Laboratório de Informática, houve também redução no uso de papel e a substituição dos dicionários, atlas e outros livros impressos por material equivalente disponível em aplicativos.

Houve um trabalho de divulgação e orientação com alunos e pais, na qual os próprios alunos criaram um contrato didático referente ao uso dos celulares na escola. Foram feitas formações discentes que resultaram em uma Escola de Líderes, com dois representantes de cada turma que realizam encontros mensais de socialização com os demais alunos.

Para melhor aproveitamento do planejamento realizado, a gestão colaborativa fez avaliações do percurso a cada etapa, prevendo melhorias para as etapas seguintes.

As dificuldades relatadas foram, principalmente, em torno de pais e professores resistentes a mudanças. Os pais, por já terem incutido o paradigma de que o uso do celular na escola é proibido, muitas vezes não aceitavam as novas práticas da escola. Professores mais antigos e tradicionais também se mostraram resistentes de início, porém, ambos foram orientados pela gestão e participaram das formações, podendo perceber os benefícios e facilidades que a prática traria para toda a comunidade. Foi relatado também problema de maturidade de alguns alunos para com o uso consciente do celular, mas nada que atrapalhasse o andamento da prática e que, ao longo dos meses, não tenha sido mudado nos próprios alunos.

Sabe-se que não é uma mudança que ocorre do dia para a noite, mas sim uma mudança de cultura e paradigma que ocorre pouco a pouco. Ao longo dos anos de 2018 e 2019 a cultura digital foi ficando mais forte na escola e, em 2020, com o início da pandemia do COVID-19, onde muitas escolas, professores e gestores tiveram imensas dificuldades para dar andamento às atividades de forma não presencial, a Escola Básica Prof. ${ }^{a}$ Maria Dutra Gomes saiu na frente desviando das dificuldades, por já ter a cultura bem estabelecida e por todos os professores e alunos estarem devidamente capacitados e ambientados ao uso das ferramentas digitais para dar andamento às atividades.

Pode-se ver que uma realidade ainda distante para muitos professores, que é a questão da familiarização com as ferramentas digitais, pode ocorrer de forma prática, planejada e com sucesso, trazendo a cultura digital como uma nova competência indispensável, utilizando todo o conhecimento que está aberto e disponível online para benefício próprio e da comunidade escolar como um todo. A quebra de paradigma em relação ao uso do celular e tecnologias foi primordial, pois quebrou muitas barreiras e elevou os processos da escola para outro patamar. 


\section{CONSIDERAÇÕES FINAIS}

Podemos observar, em apenas dois exemplos, boas práticas que têm sido desenvolvidas nas escolas brasileiras no intuito de melhorar os processos de gestão escolar e integrar comunidade, escola e alunos. Atitudes que focam no desenvolvimento individual, considerando suas especificidades e envolvendo a todos de forma consciente e colaborativa.

A gestão compartilhada do Professor Paulo, utilizando-se das tecnologias, exemplifica perfeitamente o exposto por Coelho e Unglaub $^{[5]}$, no sentido de uma instituição que buscou mudar o ambiente pedagógico e institucional com a finalidade de criar uma nova cultura, individual e coletivamente referenciada, com práticas que se aproximam e se contradizem ao mesmo tempo, servindo como um espaço extremamente inovador e que só trouxe benefícios a todo o entorno escolar.

Ao mesmo tempo, temos no Projeto Acolher para todos envolver e aprender, mudanças menos tecnológicas, mas muito significativas para a comunidade escolar, que passou de vulnerável e excluída, para inclusiva, diversa e inovadora. Mesmo com as inovações apresentadas nos processos de gestão, ainda há uma luta constante por mínimas melhorias na gestão das escolas no Brasil. Percebemos que o simples fato da troca de carteiras individuais e enfileiradas por mesas redondas e coletivas, em conjunto com outras ações, foi considerado uma inovação digna de prêmio.

Apesar de ações extremamente relevantes para a inovação na gestão escolar, a crítica acontece na literatura clássica, como Dewey ${ }^{[16]}$ expôs sobre o arranjo das carteiras em sala de aula, enfileiradas, fazendo alusão à restrição da liberdade intelectual e moral. É preciso que a educação estimule a liberdade intelectual e individual, acolhendo diferenças e sabendo que cada indivíduo tem uma forma diferente de aprendizado. Ao contrário, percebemos que a grande maioria das escolas ainda não progrediu neste mínimo aspecto e ainda usa as carteiras individuais e enfileiradas.

Este breve exemplo, nos mostra como não só a gestão, mas grande parte dos processos educacionais estão defasados e, principalmente, que já é sabido e discutido em diversas literaturas quais os paradigmas que rondam os processos inovativos em gestão e na educação como um todo. Se faz necessário a mudança e transição do aspecto fabril, na qual tudo deve ser padronizado, seguindo procedimentos e planos predeterminados, se inspirar com os autores que permeiam a temática e com os exemplos que são divulgados, tirar as ideias do papel e pô-las à prática.

A partir do meu olhar, como administradora, percebo que muitos dos problemas de gestão escolar atuais, como nos processos administrativos de entrega de merendas, controle de estoque, chamadas e planos de aula, pedidos de compras e de reformas/melhorias e processos de gestão em geral, poderiam ser resolvidos, ou simplesmente otimizados, com o uso de planilhas online e ferramentas digitais disponíveis gratuitamente. Quem exerce um cargo de gestão precisa ser proativo e a falta desta característica gera a falta de interação, a demora em resolver problemas e torna o processo mais burocrático. É preciso um trabalho de forma colaborativa, sem priorizar hierarquia, sem diminuir qualquer ator do processo escolar, buscando a igualdade de vozes e visando o benefício geral, que é obtido com a melhoria dos processos de gestão.

Está mais do que claro quais as principais - e mais básicas mudanças de atitudes e processos devem ser tomadas pelos agentes da educação, sejam gestores, professores, alunos ou pais, para a melhoria da gestão e com processos que envolvem a comunidade escolar. A partir da hora que temos gestores escolares qualificados, que entendem a mentalidade que a nova configuração da sociedade nos traz, estes devem trabalhar como propagadores de boas práticas.

Sabemos que a mudança de um paradigma retrógrado para um outro mais moderno e adaptável é lenta e difícil, pois demanda de um conjunto muito grande e diverso de atores, porém, não pode ser deixada de lado, nem esquecida, para que o movimento não perca a força e que, ao longo do tempo, seja prova do bom funcionamento $\mathrm{e}$ de bons resultados em todo o entorno da comunidade escolar.

Agradecemos ao Programa de Bolsas Universitárias de Santa Catarina, por viabilizar a especialização em Inovação na Educação e a riqueza da troca de conhecimentos obtida.

\section{REFERÊNCIAS}

[1] AMORIM, A. 2015. Gestão escolar e Inovação educacional: A construção de novos saberes gestores para a transformação do ambiente educacional na contemporaneidade. Reunião Anual Da Anped, (37) (Out.2015), http://37reuniao.anped.org.br/wp-content/uploads/2015/02/Trabalho-GT093967.pdf

[2] BEZERRA, C. 2011. A máquina de inovação: mentes e organizações na luta por diferenciação. Bookman, Porto Alegre.

[3] AMORIM, A. 2017. Gestor escolar inovador: educação da contemporaneidade. Revista Lusófona de Educação, (35) (2017), 67-82. https://www.redalyc.org/articulo.oa? $\mathrm{id}=34951149005$

[4] OGAWA, M. N.; FILIPAK S.T. 2013. A Formação do Gestor Escolar. Congresso Nacional De Educação - EDUCERE, (11) (Set.2013), https://educere.bruc.com.br/arquivo/pdf2013/8010_7046.pdf

[5] COELHO, A. de S.; UNGLAUB, E. 2012. Gestão Escolar e Inovação: Novas tendências em gestão escolar a partir das teorias em gestão da inovação. Conferência Fórum da Gestão do Ensino Superior nos Países e Regiões da Lingua Portuguesa, (2) (Nov.2012), https://www.aforges.org/wpcontent/uploads/2017/03/Coelho-Adriano-et-Unglaub-UNASP-BR.pdf

[6] VASCONCEllos, M. de N. M. de B. 2009. Gestão de Sistemas Educacionais. IESDE Brasil, Curitiba.

[7] MARTINS, E. C. 2006. Ideias e Tendências Educativas no Cenário Escolar: Onde estamos, para onde vamos? Revista Lusófona de Educação, vol. 7, (7) (Set.2006), https://revistas.ulusofona.pt/index.php/rleducacao/article/view/803

[8] ANTUNES, R. T. 2008. O gestor escolar. Programa de desenvolvimento educacional: Caderno de Gestão, (2008) http://www.gestaoescolar.diaadia.pr.gov.br/arquivos/File/producoes_pde/md_ro smeiri_trombini.pdf

[9] SOUZA, Â. R. 2009. Perfil da gestão escolar no Brasil. Revista Iberoamericana de Educación, (49/2) (Abr.2009), https://www.researchgate.net/publication/28291737

[10] HORA, D. L. da. 1994. Gestão democrática na escola: Artes e ofícios de participação. Papirus, Campinas.

[11] KRIPKA, R. M. L.; SCHELLER, M.; BONOTTO, D. de L. 2015. Pesquisa documental: considerações sobre conceitos e características na Pesquisa Qualitativa. Congresso Ibero-Americano em Investigação Qualitativa, (6) (Ago,2015),

243-247. https://proceedings.ciaiq.org/index.php/ciaiq2015/article/view/252/248

[12] FERREIRA, E. M.; ARAÚJO, C. L.; FORNARI, L. F. 2020. A compreensão de temas das ciências sociais por meio da pesquisa qualitativa. REVES - Revista Relações Sociais, vol. $\quad 3$, (2) (Abr.2020). https://periodicos.ufv.br/reves/article/view/10027/5527 
[13] SEVERINO, A. J. 2007. Metodologia do Trabalho Científico. 23. ed. rev. e atual. Cortez, São Paulo.

[14] MARCONI, M. A.; LAKATOS, E. M. 2010. Fundamentos de Metodologia Científica. 7. ed. Atlas, São Paulo.

[15] CERVO, A. L.; BERVIAN, P.A. 1983. Metodologia Científica. 3. ed. McGrawHill do Brasil, São Paulo.

[16] DEWEY, John. 2010 (1938). Experiência e Educação. Vozes, Petrópolis.

\section{ACM Reference format:}

FirstName Surname, FirstName Surname and FirstName Surname. 2018. Insert Your Title Here: Insert Subtitle Here. In Proceedings of ACM Woodstock conference (WOODSTOCK'18). ACM, New York, NY, USA, 2 pages. https://doi.org/10.1145/1234567890

[1] Patricia S. Abril and Robert Plant, 2007. The patent holder's dilemma: Buy, sell, or troll? Commun. ACM 50, 1 (Jan, 2007), 36-44. DOI: https://doi.org/10.1145/1188913.1188915. 